\title{
Extracellular heat shock protein 70 is a mortality predictor in patients with septic shock and is associated with the APACHE II and SOFA scores, and the pro-inflammatory immune response
}

\author{
PATRICIA BAUTISTA-CARBAJAL ${ }^{1 *}$, PABLO DUARTE-MOLINA ${ }^{2 *}$, INDIRA ISAMARA CONTLA-MARTÍNEZ ${ }^{1}$, \\ MIGUEL LEONARDO GARCÍA-LEÓN ${ }^{1}$, ANTONIO HUMBERTO ANGEL-AMBROCIO ${ }^{1}$, \\ NEYLA BALTAZAR-LÓPEZ ${ }^{2}$ and ROSA MARÍA WONG-CHEW ${ }^{1}$ \\ ${ }^{1}$ Infectious Diseases Research Laboratory, Research Division, Faculty of Medicine, \\ National Autonomous University of Mexico, 04510 Mexico City; \\ ${ }^{2}$ Infectious Diseases Intensive Care Unit and Central Laboratory, \\ General Hospital of Mexico Dr. Eduardo Liceaga, 06726 Mexico City, Mexico
}

Received September 25, 2020; Accepted April 8, 2021

DOI: 10.3892/wasj.2021.101

\begin{abstract}
The aim of the present study was to determine the association between extracellular heat shock protein (eHsp70) levels with mortality in adult patients with septic shock, as well as the association between eHsp70 levels and the APACHE II and SOFA scores, and the cytokines inflammatory response. The present study was an observational, longitudinal, prospective, cohort study. Adult patients with septic shock admitted to the intensive care unit (ICU) were included in the study; the eHsp70 levels were measured in sera by ELISA, and the APACHE II and SOFA scores were determined upon admission and every two days until death or discharge for improvement. The levels of pro-inflammatory cytokines were measured at baseline and at discharge. A total of 90 patients were included, 53 males and 37 females. In total, $50 \%(n=45)$ patients succumbed to the disease. Upon admission to the ICU, the eHsp70 levels (mean $\pm \mathrm{SE}$ ) were higher in the deceased patients $(1,963 \pm 461.9)$ compared with those in the survivors $(1,499 \pm 482.0, \mathrm{P}=0.02)$. ROC curve analysis for predicting mortality revealed that the eHsp70 concentration during admission to the ICU exhibited an area under the curve of 0.63 , despite Kaplan-Meier analysis, which revealed that the two higher quartiles of Hsp70 levels predicted an early mortality. Higher APACHE II and SOFA scores, as well as interleukin (IL)-6 (2,229 \pm 687 vs. 1,116 \pm 441 ,
\end{abstract}

Correspondence to: Dr Rosa María Wong-Chew, Infectious Diseases Research Laboratory, Research Division, Faculty of Medicine, National Autonomous University of Mexico, 6th Floor Research Tower, School Circuit, University, 04510 Mexico City, Mexico

E-mail: rmwong@unam.mx

*Contributed equally

Key words: heat shock protein 70, mortality, septic shock, APACHE II, SOFA, pro-inflammatory cytokines, adults
$\mathrm{P}=0.03), \mathrm{IL}-8(995 \pm 310$ vs. $206 \pm 88, \mathrm{P}=0.005)$ and $\mathrm{IL}-18$ $(1,482 \pm 314$ vs. $664 \pm 150, P=0.001)$ levels were found in the deceased patients. Thus, the present study demonstrates that high levels of eHsp70, and high APACHE II and SOFA scores, as well as a higher pro-inflammatory response is associated with mortality. eHsp70 may thus prove to be a marker of severity in adult patients with septic shock.

\section{Introduction}

Sepsis is a response to infection, that according to the 'Sepsis-3' consensus, can be derived from an inflammatory response to a potentially fatal organ dysfunction caused by a dysregulated immune response from the host to the infection (1). During the development of sepsis, a 'cytokine storm' occurs, which is probably responsible for the signs and symptoms associated with the infection (2). Clinically, septic shock is an inappropriate activation of vasodilator mechanisms and the concomitant failure of vasoconstrictor mechanisms. Hypotension and tissue hypoxia are the dominant factors and can lead to the development of a multiple organ dysfunction syndrome. Septic shock is the primary cause of mortality in intensive care units (ICUs) in all age groups worldwide, with a very high cost (3).

To determine the severity of the condition and patient outcome, some scores have been developed such as Acute Physiology and Chronic Health Evaluation (APACHE) II (4) and Sequential Organ Failure Assessment (SOFA) (5). These scores require extensive laboratory workup and clinical evaluations that are time-consuming. Other diagnostic and prognostic markers have been studied, including procalcitonin, tumor necrosis factor (TNF)- $\alpha$, interleukin (IL)-6, IL8, E-selectin, adhesion molecule 1 and leukocyte elastase, among others; however, their prognostic value is controversial (6). The early recognition and diagnosis of the severity of septic shock are crucial to improve the clinical outcome.

On the other hand serum cortisol, prolactin, heat shock protein (Hsp)70 and extracellular Hsp90 (eHsp90) levels 
increase rapidly in adult (7) and pediatric patients (8). Hsp70 is a heat shock protein involved in the folding of mature proteins. However, its function is not completely intracellular; Hsp70 can be secreted from cells in the absence of cellular necrosis, or Hsp70 can be produced in the liver and spleen as an acute phase molecule and released into the circulation to facilitate the elimination of the dying cells (9). Furthermore, the expression of Hsp70 can be stimulated by the presence of fever (10). A positive association has been observed between the serum levels of extracellular Hsp70 and markers of inflammation, indicating that extracellular Hsp70 is involved in inflammatory pathologies (11). In addition, an increase in the serum levels of Hsp70 has been shown to be associated with mortality in patients with sepsis (12).

The aims of the present study were to determine whether serum eHsp70 is a prognostic factor of short-term mortality in critically ill subjects with septic shock, as well as whether eHsp70 correlates with the SOFA and APACHE II scores, and whether it is positively asosciated with pro-inflammatory cytokine levels.

\section{Patients and methods}

Ethics. The present study was approved by the Research and Ethics Committees of the Hospital General de Mexico 'Dr. Eduardo Liceaga' (DI/16/405/04/141) and the Faculty of Medicine, Universidad Nacional Autónoma de México (064/SR/2017). The patients were invited to participate and, if they were unconscious, the patients' guardians were invited to have their relative participate in the study; written informed consent was obtained prior to inclusion.

Study population. Subjects with a diagnosis of septic shock, according to the sepsis consensus [clinically identified by persisting hypotension from infectious origin requiring vasopressors to maintain a mean arterial pressure of $\geq 65 \mathrm{mmHg}$ and a serum lactate level $>2 \mathrm{mmol} / 1$ ( $>18 \mathrm{mg} / \mathrm{dl})$ despite adequate volume resuscitation], $>18$ years old admitted to the Emergency Department, Infectious Diseases or Pneumology ICU of the Hospital General de Mexico 'Dr. Eduardo Liceaga', with the guardians' signed informed consent were included in the present study from February, 2017 to February, 2018. All patients received the standard of care treatment for septic shock, including IV fluids, antibiotics, vasopressors, or the pharmacological treatment required according to the clinical evolution. The exclusion criteria included history of $>72 \mathrm{~h}$ of septic shock, patients transferred from other units, or not having the signed informed consent by the individual or the guardian. Healthy subjects $>18$ years old, mainly students, nurses or doctors who worked at the hospital were also included as the controls to measure the baseline Hsp70 levels and cytokine levels.

Study procedures. A prospective, longitudinal, observational, cohort study was performed. Blood draws were obtained to perform a complete blood count (CBC), blood chemistry, liver function tests (LFT), procalcitonin, coagulation and gasometry tests, creatinine clearance at 24-h urine collection, at the Central Laboratory as routine tests as well as serum samples to analyze the eHsp70 protein levels and the human cytokine inflammation panel at the Infectious Diseases Research Laboratory, Research Division, Faculty of Medicine, National Autonomous University of Mexico. Clinical, demographic characteristics and comorbidities were recorded in a special format designed for the present study; the APACHE and SOFA scores were determined and recorded every day.

Enzyme-linked immunosorbent assay (ELISA) for detection of eHsp70 levels. The protein levels of eHsP70 were determined using an ELISA kit (ADI-EKS-715, Enzo Life Sciences) according to the manufacturer's instructions. Briefly, a whole blood sample from each subject was obtained. Serum was collected, aliquoted, and stored at $-70^{\circ} \mathrm{C}$ until use. The eHsp70 standard was diluted in sample diluent to generate a standard curve with six points and sample diluent alone as 0 ; prepared standards and undiluted serum were added to a 96-well plate pre-coated with mouse monoclonal antibody specific for eHsp70 and incubated for $2 \mathrm{~h}$ at room temperature. The anti-eHsp70 goat polyclonal antibody was then added to each well and incubated for $1 \mathrm{~h}$ at room temperature; after rinsing, horseradish peroxidase-conjugate anti-goat IgG was added to the plate and incubated for $1 \mathrm{~h}$ at room temperature, followed by the addition of $100 \mu \mathrm{l}$ of 3,3',5,5'-tetramethylbenzidine substrate for $30 \mathrm{~min}$ in the dark. Finally, Stop Solution was added, and absorbance was measured at $450 \mathrm{~nm}$ in a microplate photometric reader MultisKan FC (Thermo Fisher Scientific, Inc.).

Cytokine assays. The serum concentrations of interferon (IFN)- $\gamma$, IL-1 $\beta$, IL-6, IL-8 (CXCL8), IL-10, IL-12p70, IL-18 and TNF- $\alpha$ were measured using the BioLegend LEGENDplex Human Inflammation Panel (8-plex) kit (cat. no. 740809, BioLegend, Inc.) using the 'Attune' NxT Flow Cytometer (Thermo Fisher Scientific, Inc.). The assays were performed according to the manufacturer's instructions. Briefly, serum or standard was added to a V-bottom 96-well plate and mixed with assay buffer, beads and biotinylated detection antibody mix and incubated for $2 \mathrm{~h}$ at room temperature on a shaker at $600 \mathrm{rpm}$, rinsed twice and read with an Attune NxT Flow Cytometer (Thermo Fisher Scientific, Inc.).

The bead populations were identified by FSC/SSC features and fluorescence intensity in the APC channel. Approximately 400 beads per analyte were acquired using LEGENDplex ${ }^{\mathrm{TM}}$ Data Analysis Software (version 8, BioLegend, Inc.). The concentrations of these cytokines in serum were calculated from the standard curves of known concentrations of recombinant human cytokines $(\mathrm{pg} / \mathrm{ml})$.

Statistical analysis. Sample size calculation was made on Epi Info based on a previous study (13) with $45 \mathrm{ng} / \mathrm{ml}$ in $14 \%$ mortality compared to $78 \mathrm{ng} / \mathrm{ml}$ in $86 \%$ survivors with septic shock, with an $\alpha$ value of 0.05 , power $80 \%, 20 \%$ of detection in controls and $50 \%$ detection in cases giving a total of 90 cases, 45 for exposed and unexposed. Central tendecy measures were used for demographic, clinical characteristics, and Hsp70 and cytokine levels; a Student's t-test or Mann-Whitney U test were used to contrast two quantitative variables, and ANOVA or the Kruskal-Wallis test were used for the comparisons of three or more groups of quantitative 
Table I. Demographic comorbidities and clinical characteristics of patients with septic shock.

\begin{tabular}{|c|c|c|c|}
\hline Cormobidity/characteristic & Survivors $(\mathrm{n}=45)$ & Deceased $(n=45)$ & P-value \\
\hline Male n $(\%)$ & $27(60)$ & $26(57.7)$ & 0.83 \\
\hline Female n $(\%)$ & $18(40)$ & $19(42.2)$ & \\
\hline Age (years, mean $\pm \mathrm{SE}$ ) & $50.22 \pm 2.07$ & $48.4 \pm 1.98$ & 0.336 \\
\hline Height $(m$, mean \pm SE) & $1.62 \pm 0.011$ & $1.63 \pm 0.012$ & 0.709 \\
\hline Weight $(\mathrm{kg}$, mean $\pm \mathrm{SE})$ & $68.79 \pm 2.52$ & $69.50 \pm 2.52$ & 0.514 \\
\hline $\mathrm{BMI}$, mean $\pm \mathrm{SE}$ & $25.56 \pm 0.93$ & $26.68 \pm 0.94$ & 0.328 \\
\hline \multicolumn{4}{|l|}{ Comorbidities } \\
\hline Cancer & $5(11.11)$ & $3(6.67)$ & 0.459 \\
\hline $\mathrm{DM}$ & $12(35.56)$ & $19(33.33)$ & 0.824 \\
\hline Being overweight & $17(37.78)$ & $9(20)$ & 0.063 \\
\hline Obesity & $9(20)$ & $9(20)$ & ns \\
\hline SH & $10(22.22)$ & $5(11.11)$ & 0.157 \\
\hline CRF & $4(8.89)$ & $5(11.11)$ & 0.725 \\
\hline ARF & $8(17.78)$ & $7(15.56)$ & 0.081 \\
\hline HIV & $4(8.89)$ & $10(22.22)$ & 0.396 \\
\hline \multicolumn{4}{|l|}{ Clinical characteristics } \\
\hline APACHE II (mean \pm SE) & $24.27 \pm 8.85$ & $31.60 \pm 6.29$ & 0.001 \\
\hline $\mathrm{SOFA}($ mean $\pm \mathrm{SE})$ & $10.76 \pm 2.95$ & $13.29 \pm 3.20$ & 0.001 \\
\hline Procalcitonin $(\mathrm{ng} / \mathrm{ml}$, mean $\pm \mathrm{SE})$ & $24.26 \pm 6.98$ & $32.45 \pm 9.86$ & 0.101 \\
\hline Leukocytes $\left(10^{3} / \mu 1\right.$, mean $\left.\pm \mathrm{SE}\right)$ & $17.03 \pm 1.70$ & $15.87 \pm 1.13$ & 0.008 \\
\hline Hospitalization (days, mean \pm SE) & $6.31 \pm 0.84$ & $4.13 \pm 0.58$ & 0.006 \\
\hline
\end{tabular}

BMI, body mass index; DM, diabetes mellitus; SH, systemic hypertension; ARF, acute renal failure; HIV, infection with human immunodeficiency virus; CRF, chronic renal failure; APACHE, Acute Physiology and Chronic Health Evaluation; SOFA, Sequential Organ Failure Assessment; ns, not significant. Chi-squared test and t-test were used to analyze the qualitative or quantitative variables, respectively.

variables. The Chi-squared was used to analyze qualitative variables, and Spearman's correlation analysis was performed to determine the correlation between the APACHE, SOFA and Hsp70 levels. ROC curves and Kaplan-Meier analysis for mortality and the days of hospitalization based on quartiles of eHsp70 values were performed and the Breslow test was used to contrast the mortality and Hsp70 levels. A value of $\mathrm{P}<0.05$ was considered to indicate a statistically significant difference.

\section{Results}

Clinical and demographic characteristics. A total of 90 patients were included in the present study, with a mean age of $49.31 \pm 2.03$ years, 53 males and 37 females. In total, $50 \%(n=45)$ of the patients succumbed to the disease. No marked differences in the baseline characteristics, including sex, age, height, weight or body mass index (BMI) were observed between the patients who were deceased and those who survived (Table I). A total of 25 healthy subjects were included as the control group for the baseline eHsp70 levels and cytokine levels.

The comorbidities examined were diabetes mellitus (DM), being overweight, obesity, systemic hypertension ( $\mathrm{SH}$ ), acute renal failure (ARF), human immunodeficiency virus infection (HIV), chronic renal failure (CRI) and cancer, with no significant differences observed between the groups (Table I).
The APACHE II $(31.60 \pm 6.29$ vs. $24.27 \pm 8.85, \mathrm{P}=0.001)$ and SOFA $(13.29 \pm 3.20$ vs. $10.76 \pm 2.95, \mathrm{P}=0.001)$ scores were higher in the deceased patients compared with those of the survivors. The leukocyte count was lower in the deceased patients $(15.87 \pm 1.13$ vs. $17.03 \pm 1.70, \mathrm{P}=0.008)$. Similarly, the days of hospitalization were lower in the deceased patients $(4.13 \pm 0.58$ vs. $6.31 \pm 0.84, \mathrm{P}=0.006)$. The procalcitonin levels did not exhibit any marked differences between groups (Table I).

Hsp70 levels upon ICU admission, and their association with severity scores and outcome. Upon admission to the ICU, the eHsp70 levels (mean $\pm \mathrm{SE}, \mathrm{pg} / \mathrm{ml}$ ) were higher in the deceased patients $(1,963 \pm 461.9)$ compared with those of the survivors $(1,499 \pm 482.0, \mathrm{P}=0.02)$ and healthy individuals $(496.9 \pm 230.9$, $\mathrm{P}=0.0004$ ) (Kruskal-Wallis test, $\mathrm{P}=0.001$ ) (Fig. 1A). A positive correlation was observed between the eHsp70 levels upon admission to the ICU and the SOFA scores in the survivors $\left(\mathrm{R}^{2}=0.36, \mathrm{P}<0.05\right)$ and in the deceased patients $\left(\mathrm{R}^{2}=0.37\right.$, $\mathrm{P}<0.001)$. A positive correlation was also observed between the eHsp70 levels and the APACHE II score in the survivors $\left(\mathrm{R}^{2}=0.36, \mathrm{P}<0.05\right)$ and in the deceased patients $\left(\mathrm{R}^{2}=0.45\right.$, $\mathrm{P}=0.004)$ (Fig. 1B and $\mathrm{C}$ ).

ROC curve analysis for predicting mortality revealed that the eHsp70 concentration upon admission to the ICU had a discriminative survival capacity with an area under the curve (AUC) of 0.64 (95\% CI, 0.522-0.754) (Fig. 2). 

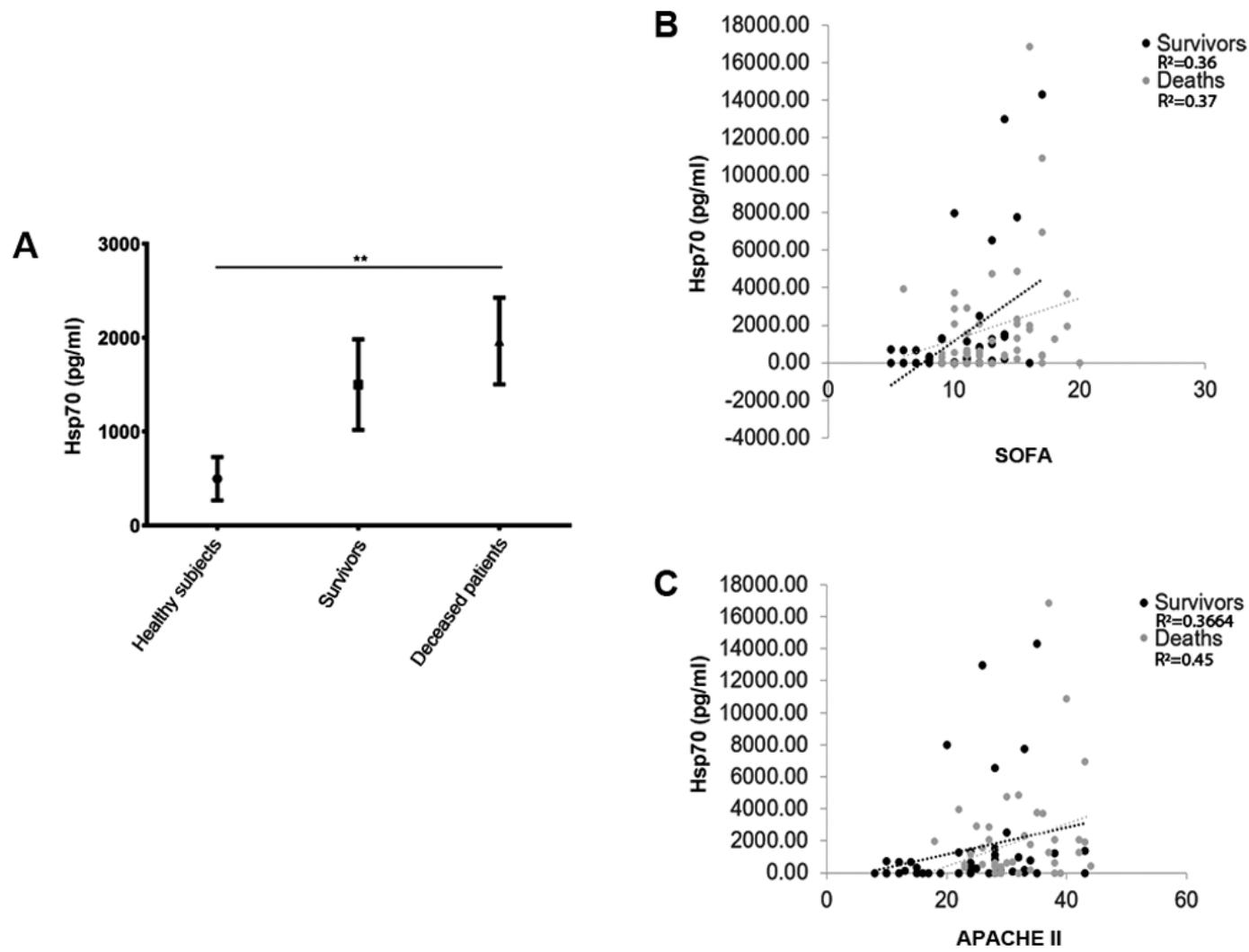

Figure 1. (A) Serum levels of Hsp70 upon admission to the ICU. Survivors, 1,963 \pm 461.9 ; deceased patients, 1,499 \pm 482.0 ; healthy individuals, $496.9 \pm 230.9$. ${ }^{* *} \mathrm{P}<0.005$ (Kruskal-Wallis test). (B) Correlation between the Hsp70 serum concentration and the index SOFA at admission to the ICU. Survivors, $\mathrm{R}^{2}=0.36$, $\mathrm{P}<0.05$; deceased patients, $\mathrm{R}^{2}=0.37, \mathrm{P}<0,001$. (C) Correlation between the Hsp70 serum concentration and the index APACHE II upon admission to the ICU. Survivors, $R^{2}=0.3664, P<0.05$; deceased patients, $R^{2}=0.45, P=0,004$. Black dots and black dotted lines represent survivors, and grey dots and grey dotted lines represent deceased patients. Hsp70, heat shock protein 70; ICU, intensive care unit; APACHE, Acute Physiology and Chronic Health Evaluation; SOFA, Sequential Organ Failure Assessment.

The Breslow test based on the Kaplan-Meier curves revealed a significant association between high eHsp70 levels and mortality, and was used as it gives more weight to mortality at early stages ( $\mathrm{P}=0.031$; Fig. 3 ), with the two upper quartiles associated with mortality in the first couple of days, with $570 \mathrm{pg} / \mathrm{ml}$ being the lower value of the 3 rd quartile.

Cytokine levels in patients with septic shock. Upon ICU admission, the IL-6 (2,229 \pm 687 vs. $1,116 \pm 441, \mathrm{P}=0.03)$, IL-8 $(995 \pm 310$ vs. $206 \pm 88, \mathrm{P}=0.005)$ and IL-18 $(1,482 \pm 314$ vs. $664 \pm 50$, $\mathrm{P}=0.001$ ) levels were higher in the patients who had succumbed to the disease compared with those of the survivors; at the time of discharge, the levels of IL-6 (1,642 \pm 587 vs. $196 \pm 6, \mathrm{P}=0.008)$ and IL-8 $(530 \pm 219$ vs. $89 \pm 28, P=0.03)$ were also higher in the patients who had succumbed to the disease compared with those of survivors (Fig. 4).

\section{Discussion}

The consensus for sepsis treatment 'Surviving Sepsis Campaign: International Guidelines for Management of Severe Sepsis and Septic Shock 2016' highlights the importance of the early recognition of septic shock to implement an early treatment and decrease mortality (14). In the present study, the baseline level of eHsp70 upon admission to the ICU was higher in the deceased patients with septic shock compared with the survivors and healthy controls. Although the AUC

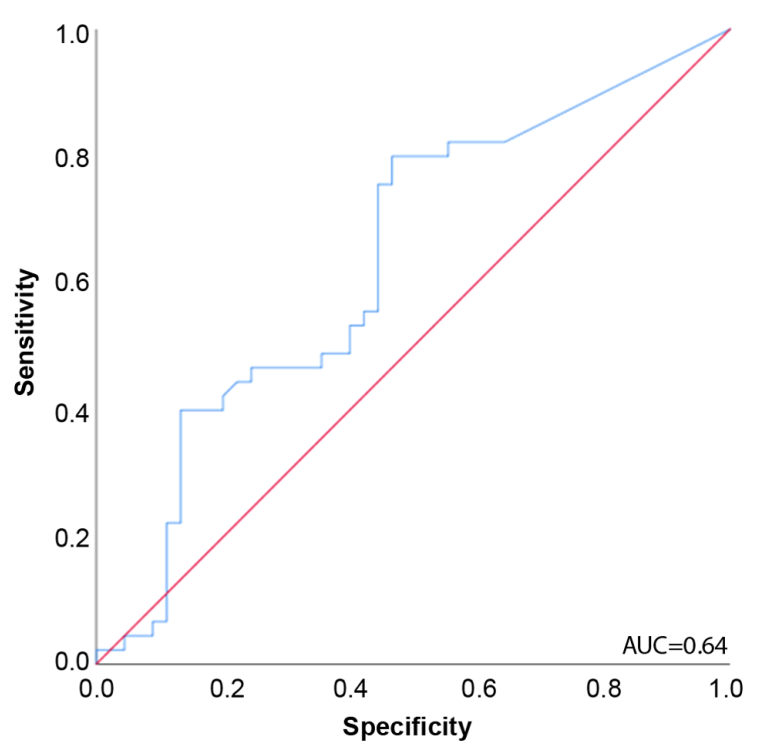

Figure 2. ROC curves for the prediction of mortality in patients with septic shock $(n=90)$. The area under the ROC curve was 0.64 . ROC, receiver operating characteristic; AUC, area under the curve.

was $64 \%$, which is a regular predictor, the two upper quartiles of eHsp70 were associated with mortality in the first days of admission to the ICU; the upper quartile values $>1,800 \mathrm{pg} / \mathrm{ml}$ with $45 \%$ of mortality in the first two days and the 3rd quartile 


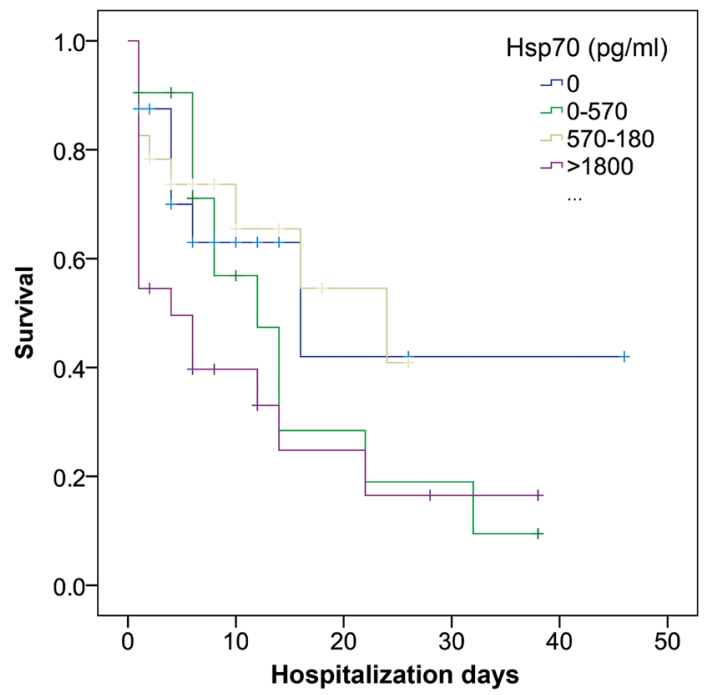

Figure 3. Kaplan-Meier curves for the incidence of mortality in patients with septic shock, stratified according to interquartile range of soluble Hsp70 (Breslow test, $\mathrm{P}=0.03$ ). Hsp70, heat shock protein 70 .

values ranged from 580 to $1,800 \mathrm{pg} / \mathrm{ml}$ with $18 \%$ mortality in the first two days.

Hsp70 is involved in several biological functions, such as apoptosis, carcinogenesis, protection against cytotoxic damage and immunopathological events associated with bacterial infections (15). The exposure of the cells to physical or chemical stress results in a greater synthesis of Hsp70 (16) with a positive feedback regulation of Hsp70 induction in innate immune cells (17). The increase in the serum levels of Hsp70 reflects a systemic inflammation and oxidative stress, that can decrease inflammatory reactions mediated by $\mathrm{T}$ cells in many clinical conditions (18).

Regulatory T cells (Tregs) suppress the immune response, thereby maintaining homeostasis and self-tolerance. The suppression of Tregs enhanced by extracellular Hsp70 can prevent increased immune responses and may play an important role in the maintenance of homeostasis (19). eHsp70 can act as damage-associated molecular pattern (DAMP) via the Toll-like receptors (TLRs), TLR2 and TLR4, and stimulate inflammatory responses (20).

Heat shock proteins modulate the expression of pro-inflammatory cytokines by inhibiting the translocation of $N F-\kappa B$ to the nucleus (19-21). However, in patients with sepsis, the mechanism of the expression of Hsp70 related to inflammatory mediators and the prognosis is not yet well understood (22).

Schroeder et al (23) found that Hsp70 expression was lower in peripheral blood lymphocytes of patients with severe sepsis compared with that of healthy controls or post-operative patients. By contrast, in the present study, the serum concentrations of eHsp70 were markedly higher $(1,963 \pm 461.9 \mathrm{pg} / \mathrm{ml})$ in deceased patients, which could reflect higher levels of inflammation and cell apoptosis. The 'danger hypothesis' suggests the release of Hsp70 from severely stressed or damaged cells, which serves as a danger signal to neighboring cells (23-25). This increase in Hsp70 serum levels has been previously reported in children with septic shock and has been suggested to be a predictive marker of severity (13). In the present study, ROC curve analysis for predicting mortality revealed that the Hsp70 concentration upon admission to the ICU had a discriminative survival capacity with an (AUC of 0.64 (95\% CI, 0.522-0.754). It is important to consider that the analysis of the AUC has limitations compared to other statistical methods for analyzing biomarkers (26). Hsp70 is a protein that responds to multiple stimuli and in other studies, an area under the relatively low curve when analyzing Hsp70 as a possible biomarker for various diseases was observed (27-29). However, it has been considered a good candidate for the detection of sepsis. The predictive capacity of the marker could increase if other molecules are also analyzed.

The APACHE II and SOFA scores are models which can be used to measure the severity of critically ill patients and to predict mortality (30). In the present study, high levels of eHsp70 are found to positively correlate with APACHE II and SOFA scores; thus this protein may be a good predictive marker of the severity of sepsis.

Among the numerous pro-inflammatory cytokines studied during sepsis, IL-1 $\beta$, IL-6, IL-12 and IL-17 have been reported (31). IL-1 $\beta$ promotes a signaling cascade and induces the synthesis of various inflammatory cytokines, such as IL-6, IL-8, monocyte chemoattractant protein-1 (MCP-1), cyclooxygenase 2 (COX)-2, inhibitor $\kappa \mathrm{B}-\alpha$ (I $\kappa \mathrm{B} \alpha)$, IL-1 $\alpha$, IL-1 $\beta$ and mitogen-activated protein kinase (MAPK) phosphatase 1 (MKP-1) (31). During sepsis, it has been demonstrated that IL-1 $\beta$ levels are higher in patients who do not survive (31). High levels of IL- 6 have been observed in a number of inflammatory diseases, such as cardiovascular disease, autoimmune diseases or cancer; it has been demonstrated that high levels of IL-6 and IL-8 are associated with the severity of sepsis (32-34).

In the present study, a higher inflammatory response was observed upon admission to the ICU in deceased patients, with a significant increase in the levels of the pro-inflammatory cytokines, IL-6, IL-8 and IL-18, where the IL-6 and IL-8 levels of continued to be high until death. The high levels of eHsp70 and pro-inflammatory cytokines in those who did not survive suggest constant cell damage, without a counterregulatory mechanism to decrease inflammation. Although not statistically significant, the levels of IL-10 were higher in the survivors, suggesting that this counterregulatory mechanism may partially attenuate the damage, allowing the return to homeostasis.

In the present study, leukocyte levels were also lower in deceased patients, although the inflammatory cytokine levels were higher, and the days of hospitalization were also lower, which may be due to such a high inflammatory response that caused multi-organ failure (MOF) in fewer days. It has been described that while single organ failure has no impact on long-term outcomes, the presence of MOF markedly increases mortality and the risk of an impaired functional status (35).

One limitation of the present study was the relatively small sample size $(n=90)$, despite finding statistical differences. In addition, a high proportion of patients had comorbidities, such as like HIV, diabetes, hypertension and renal failure, among others; however, due to the sample size, multivariate analysis could not be performed. However, the proportion of comorbidities in both groups did not differ significantly, which could suggest that the comorbidities had no effect on mortality. 

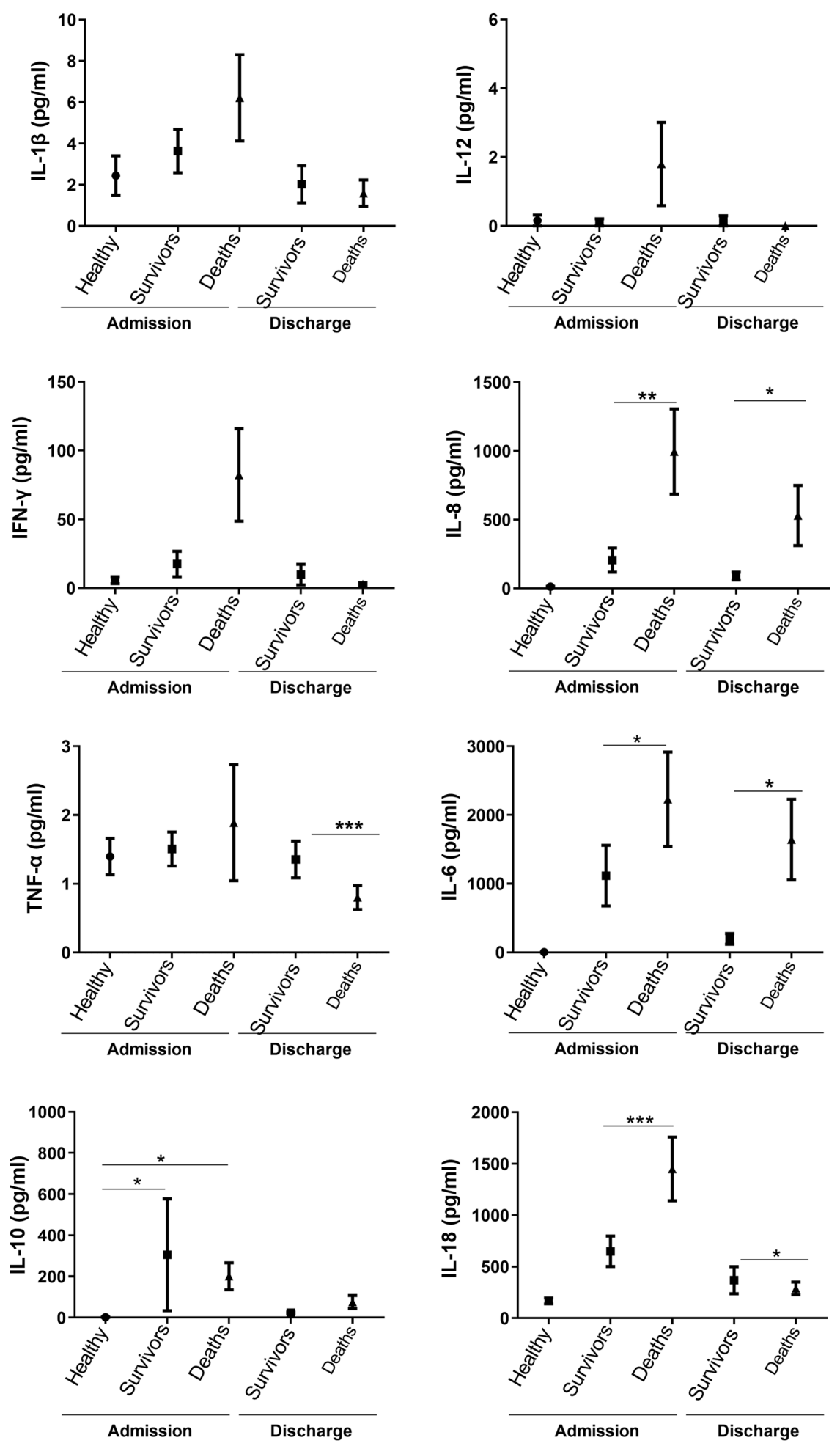

Figure 4. Comparison of serum cytokine concentrations between patients with septic shock who were discharged and those who succumbed to the disease upon admission to and discharge from the ICU. ${ }^{*} \mathrm{P}<0.05,{ }^{* *} \mathrm{P}<0.005,{ }^{* * * *} \mathrm{P}<0.001$. The Kruskal-Wallis test was used for the comparisons of three groups and the Mann-Whitney $\mathrm{U}$ test for the comparisons of two groups. The three groups upon ICU admission exhibited differences in IL-10 ( $\mathrm{P}<0.0001)$, IL-6 ( $<<0.0001$ ), IL-8 $(\mathrm{P}<0.001)$ and IL-18 ( $<<0.0001)$ levels.

In the present study, it was found that the serum eHsp70 levels upon admission to the ICU were high in adult patients with septic shock who did not survive. Additionally, the eHsp70 levels positively correlated with the APACHE II and SOFA scores, and were also positively associated with the pro-inflammatory cytokine levels. It is important to conduct further studies with eHsp70 to improve the clinical practice, timely treatment and prognosis, in order to reduce the mortality of patients with septic shock.

\section{Acknowledgements}

PBC was a Postdoctoral Fellow sponsored by the Programa de Becas Posdoctorales, Dirección General de Asuntos 
del Personal Académico, Universidad Nacional Autónoma de México. The authors would like to thank Dr Antonio Villa Romero from the Methodology Department, Research Division, Faculty of Medicine, National Autonomous University of Mexico for his assistance with part of the statistical analysis. The authors would also like thank Mrs. María Josefina Bolado Garza, Head of the Translation Department, División de Investigación, Facultad de Medicina, UNAM, for editing this manuscript.

\section{Funding}

The present study was supported by Federal Funds from the Research Division, Hospital General de México 'Dr. Eduardo Liceaga', and Federal Funds from the Facultad de Medicina, Universidad Nacional Autónoma de México.

\section{Availability of data and materials}

The datasets used and/or analyzed during the current study are available from the corresponding author on reasonable request.

\section{Authors' contributions}

RMWC, PDM and MLGL designed the study. PDM and IICM were involved in patient recruitment. IICM, NBL and PDM were involved in sample collection, processing and storage. PBC, MLGL and AHAA performed the in vitro experiments. PDM, PBC, RMWC and MLGL performed the analysis of the data and interpretation. PBC and RMWC wrote the manuscript. All the authors critically revised the manuscript. All the authors read and approved the final manuscript. PBC, PDM, MLGL, AHAA and RMWC confirm the authenticity of all the raw data.

\section{Ethics approval and consent to participate}

The present study was approved by the Ethics and Research Committees of the Hospital General de México Dr. Eduardo Liceaga (DI/16/405/04/141) and the Facultad de Medicina, Universidad Nacional Autónoma de México (064/SR/2017) and was performed following international and national regulations in accordance with the Declaration of Helsinki and the Mexican General Health Law for Research in Health. Written informed consent was obtained from all the participants.

\section{Patient consent for publication}

Not applicable.

\section{Competing interests}

The authors declare that they have no competing interests.

\section{References}

1. Singer M, Deutschman CS, Seymour CW, Shankar-Hari M, Annane D, Bauer M, Bellomo R, Bernard GR, Chiche JD, Coopersmith CM, et al: The third international consensus definitions for sepsis and septic shock (Sepsis-3). JAMA 315: 801-810, 2016.
2. Ferrara JL, Abhyankar S and Gilliland DG: Cytokine storm of graft-versus-host disease: A critical effector role for interleukin-1. Transplant Proc 25: 1216-1217, 1993.

3. Arefian H, Heublein S, Scherag A, Brunkhorst FM, Younis MZ, Moerer O, Fischer D and Hartmann M: Hospitalrelated cost of sepsis: A systematic review. J Infect 74: 107-117, 2017.

4. Knaus WA, Draper EA, Wagner DP and Zimmerman JE: APACHE II: A severity of disease classification system. Crit Care Med 13: 818-829, 1985.

5. Vincent JL, Moreno R, Takala J, Willatts S, De Mendonça A, Bruining H, Reinhart CK, Suter PM and Thijs LG: The SOFA (sepsis-related organ failure assessment) score to describe organ dysfunction/failure. On behalf of the working group on sepsis-related problems of the European society of intensive care medicine. Intensive Care Med 22: 707-710, 1996.

6. de Groot B, Stolwijk F, Warmerdam M, Lucke JA, Singh GK, Abbas M, Mooijaart SP, Ansems A, Esteve Cuevas L and Rijpsma D: The most commonly used disease severity scores are inappropriate for risk stratification of older emergency department sepsis patients: An observational multi-centre study. Scand J Trauma Resusc Emerg Med 25: 91, 2017.

7. Vardas K, Apostolou K, Briassouli E, Goukos D, Psarra K, Botoula E, Tsagarakis S, Magira E, Routsi C, Nanas S and Briassoulis G: Early response roles for prolactin cortisol and circulating and cellular levels of heat shock proteins 72 and $90 \alpha$ in severe sepsis and SIRS. Biomed Res Int 2014: 803561, 2014.

8. Fitrolaki MD, Dimitriou H, Venihaki M, Katrinaki M, Ilia S and Briassoulis G: Increased extracellular heat shock protein $90 \alpha$ in severe sepsis and SIRS associated with multiple organ failure and related to acute inflammatory-metabolic stress response in children. Medicine (Baltimore) 95: e4651, 2016.

9. Merchant S and Korbelik M: Heat shock protein 70 is acute phase reactant: Response elicited by tumor treatment with photodynamic therapy. Cell Stress Chaperones 16: 153-162, 2011.

10. Gupta A, Cooper ZA, Tulapurkar ME, Potla R, Maity T, Hasday JD and Singh IS: Toll-like receptor agonists and febrile range hyperthermia synergize to induce heat shock protein 70 expression and extracellular release. J Biol Chem 288: 2756-2766, 2013.

11. Njemini R, Demanet $\mathrm{C}$ and Mets T: Inflammatory status as an important determinant of heat shock protein 70 serum concentrations during aging. Biogerontology 5: 31-38, 2004.

12. Gelain DP, Bittencourt Pasquali MA, M Comim C, Grunwald MS, Ritter C, Tomasi CD, Alves SC, Quevedo J, Dal-Pizzol F and Moreira JCF: Serum heat shock protein 70 levels, oxidant status, and mortality in sepsis. Shock 35: 466-470, 2011.

13. Wheeler DS, Fisher LE Jr, Catravas JD, Jacobs BR, Carcillo JA and Wong HR: Extracellular hsp70 levels in children with septic shock. Pediatr Crit Care Med 6: 308-311, 2005.

14. Rhodes A, Evans LE, Alhazzani W, Levy MM, Antonelli M, Ferrer R, Kumar A, Sevransky JE, Sprung CL, Nunnally ME, et al: Surviving sepsis campaign: International guidelines for management of sepsis and septic shock: 2016. Crit Care Med 45: 486-552, 2017.

15. StruzikJ, Szulc-Dąbrowska L and Niemiałtowski M: Participation of heat shock proteins in modulation of NF- $\mathrm{NB}$ transcription factor activation during bacterial infections. Postepy Hig Med Dosw (Online) 69: 969-977, 2015 (In Polish).

16. Rokutan K: Role of heat shock proteins in gastric mucosal protection. J Gastroenterol Hepatol 15 (Suppl): D12-D19, 2000.

17. Lee KH, Jeong J and Yoo CG: Positive feedback regulation of heat shock protein 70 (Hsp70) is mediated through Toll-like receptor 4-PI3K/Akt-glycogen synthase kinase-3 $\beta$ pathway. Exp Cell Res 319: 88-95, 2013.

18. Stocki P, Wang XN and Dickinson AM: Inducible heat shock protein 70 reduces $\mathrm{T}$ cell responses and stimulatory capacity of monocyte-derived dendritic cells. J Biol Chem 287: 12387-12394, 2012.

19. Wachstein J, Tischer S, Figueiredo C, Limbourg A, Falk C, Immenschuh S, Blasczyk R and Eiz-Vesper B: HSP70 enhances immunosuppressive function of CD4(+)CD25(+)FoxP3(+) $\mathrm{T}$ regulatory cells and cytotoxicity in CD4(+)CD25(-) T cells. PLoS One 7: e51747, 2012.

20. Hulina A, Grdić Rajković M, Jakšić Despot D, Jelić D, Dojder A, Cepelak I and Rumora L: Extracellular Hsp70 induces inflammation and modulates LPS/LTA-stimulated inflammatory response in THP-1 cells. Cell Stress Chaperones 23: 373-384, 2018.

21. Wong HR, Ryan M and Wispé JR: The heat shock response inhibits inducible nitric oxide synthase gene expression by blocking I kappa-B degradation and NF-kappa B nuclear translocation. Biochem Biophys Res Commun 231: 257-263, 1997. 
22. Wong HR, Ryan M and Wispé JR: Stress response decreases NF-kappaB nuclear translocation and increases I-kappaBalpha expression in A549 cells. J Clin Invest 99: 2423-2428, 1997.

23. Schroeder S, Lindemann C, Hoeft A, Putensen C, Decker D, Ruecker AA and Stüber F: Impaired inducibility of heat shock protein 70 in peripheral blood lymphocytes of patients with severe sepsis. Crit Care Med 27: 1080-1084, 1999.

24. Vera ME, Kim YM, Wong HR, Wang Q, Billiar TR and Geller DA: Heat shock response inhibits cy tokine-inducible nitric oxide synthase expression in rat hepatocytes. Hepatology 24: 1238-1245, 1996.

25. Campisi J, Leem TH and Fleshner M: Stress-induced extracellular Hsp72 is a functionally significant danger signal to the immune system. Cell Stress Chaperones 8: 272-286, 2003.

26. Grund B and Sabin C: Analysis of biomarker data: Logs, odds ratios, and receiver operating characteristic curves. Curr Opin HIV AIDS 5: 473-479, 2010.

27. Johnson JD and Fleshner M: Releasing signals, secretory pathways, and immune function of endogenous extracellular heat shock protein 72. J Leukoc Biol 79: 425-434, 2006.

28. Zhao J, Wang T, Lv Q and Zhou N: Expression of heat shock protein 70 and Annexin A1 in serum of patients with acutely severe traumatic brain injury. Exp Ther Med 19: 1896-1902, 2020.

29. Li Z, Song Y, Xing R, Yu H, Zhang Y, Li Z and Gao W: Heat shock protein 70 acts as a potential biomarker for early diagnosis of heart failure. PLoS One 8: e67964, 2013.

30. Naqvi IH, Mahmood K, Ziaullaha S, Kashif SM and Sharif A: Better prognostic marker in ICU-APACHE II, SOFA or SAP II! Pak J Med Sci 32: 1146-1151, 2016.
31. Mera S, Tatulescu D, Cismaru C, Bondor C, Slavcovici A, Zanc V, Carstina D and Oltean M: Multiplex cytokine profiling in patients with sepsis. APMIS 119: 155-163, 2011.

32. Gouel-Chéron A, Allaouchiche B, Guignant C, Davin F, Floccard B and Monneret G; AzuRea Group: Early interleukin-6 and slope of monocyte human leukocyte antigen-DR: A powerful association to predict the development of sepsis after major trauma. PLoS One 7: e33095, 2012.

33. Wu HP, Chen CK, Chung K, Tseng JC, Hua CC, Liu YC, Chuang DY and Yang CH: Serial cytokine levels in patients with severe sepsis. Inflamm Res 58: 385-393, 2009.

34. Kellum JA, Kong L, Fink MP, Weissfeld LA, Yealy DM, Pinsky MR, Fine J, Krichevsky A, Delude RL and Angus DC; GenIMS Investigators: Understanding the inflammatory cytokine response in pneumonia and sepsis: Results of the genetic and inflammatory markers of sepsis (GenIMS) study. Arch Intern Med 167: 1655-1663, 2007.

35. Ulvik A, Kvåle R, Wentzel-Larsen T and Flaatten H: Multiple organ failure after trauma affects even long-term survival and functional status. Crit Care 11: R95, 2007.

This work is licensed under a Creative Commons Attribution-NonCommercial-NoDerivatives 4.0 International (CC BY-NC-ND 4.0) License. 